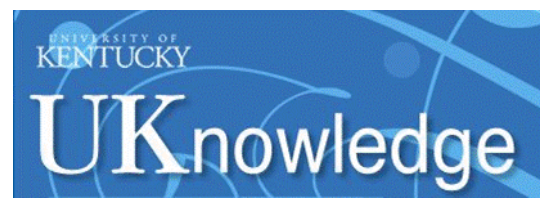

University of Kentucky

UKnowledge

\title{
A Tension Between Two Cultures ... Dentistry as a Profession and Dentistry as Proprietary
}

David A. Nash

University of Kentucky, danash@uky.edu

Follow this and additional works at: https://uknowledge.uky.edu/ohs_facpub

Part of the Dentistry Commons

Right click to open a feedback form in a new tab to let us know how this document benefits you.

\section{Repository Citation}

Nash, David A., "A Tension Between Two Cultures ... Dentistry as a Profession and Dentistry as Proprietary" (1994). Oral Health Science Faculty Publications. 12.

https://uknowledge.uky.edu/ohs_facpub/12

This Article is brought to you for free and open access by the Oral Health Science at UKnowledge. It has been accepted for inclusion in Oral Health Science Faculty Publications by an authorized administrator of UKnowledge. For more information, please contact UKnowledge@lsv.uky.edu. 
A Tension Between Two Cultures ... Dentistry as a Profession and Dentistry as Proprietary

\section{Notes/Citation Information}

Published in the Journal of Dental Education, v. 58, no. 4, p. 301-306.

Reprinted by permission of Journal of Dental Education, Volume 58, 4 (April 1994). Copyright 1994 by the American Dental Education Association. http://www.jdentaled.org 
Reprinted by permission of Journal of Dental Education, Volume 58, 4 (April 1994). Copyright 1994 by the American Dental Education Association.

http://www.jdentaled.org 


\section{A Tension Between Two Cultures... Dentistry as a Profession and Dentistry as Proprietary}

David A. Nash, D.M.D., Ed.D.

Dr. Nash is professor and dean, College of Dentistry, University of Kentucky, Lextingtom, KY $40536-0084$ (Internet david.nash (1)ukuang. uky.edu). Send correspondence and reprint requests to Dr. Nash.

\section{Two CuLTURES}

The notable English literary scholar C. P. Snow published his widely read and influential book, Tuo Cultures and the Scientific Revolution in 1959. In it he documents and discusses a cultural divide between contemporary thinkers; literary intellectuals as representatives of one pole, and scientists as exemplars of the other. He says that a "gulf of mutual incomprehension, sometimes hostility and dislike, extsts between them, but most of all a lack of understanding." Snow went on to characterize these two groups as "two cultures," and to lament the losses that derive from their inability to communicate effectively.

Recently, I have had the opportunity to meet with several groups to discuss the issue of health care reform, specifically dentistry's participation in the process and in a reformed system. My encounters have generally been unsatisfying, and have become increasingly frustrating. I have finally come to realize that in these conversations individuals have been speaking past one another, not with one another. Our inability to effectively communicate with one another concerning health care reform derives, I believe, from fundamental and basic differences we have in dentistry concerning the nature of health, and the nature of a health care profession. I have concluded that in dentistry there are two cultures. I want to be as explicit as possible about these cultural differences, with the intent of better understanding why tensions exist. Better understanding is the only hope we have for reducing the tension I sense between our two cultures.

\section{DefinING CUlture}

Understanding culture is our way of understanding people. Acknowledging the existence of different cultures is affirming that different people have different understandings about life and the world. We honor different traditions. We hold different ways of measuring and evaluating our existence and different mechanisms for assigning meaning to our existence. Let me define culture: ${ }^{2-4}$

Culture is the collective, mutually shaping patterns of norms, values, assumptions, beliefs, standards, and attitudes that guide the behavior of individuals and groups, whether those groups be families, colleagues, religions, races, geographic regions, nations, or professions.

Culture provides a construct for understanding behavior. Behavior is shaped by our shared relationships, understandings, and beliefs. Culture serves as an interpretive framework within which to determine what is valued and what is not, establish the moral imperatives that bind us to individuals, order our behavior, and determine rewards and punishments. Culture provides contextual clues necessary to interpret words and actions. Culture gives actions and events meaning. Culture enhances stability in that it permits predictability and enhances our sense of certainty. Culture permits introduction to and socialization of individuals who would become members of a cultural community. 
When we speak of the norms of a culture we are suggesting what the culture understands as normal, that which is or should occur naturally. The norms of a culture are what the culture sees as its guiding rules or principles. The values of a culture are those things which are desired. Desires create purpose-purpose provides meaning. The assumptions of a culture are what the culture takes for granted; what it is that the culture presupposes or does not bring into question; what it accepts as reality. The beliefs of a culture are those things in which the culture places its trust and confidence. Standards are the uniform referents of the culture; the touchstones the culture uses in its measuring and evaluating. Finally, attitudes are the emotional intentions of the culture; what the culture feels, and what the culture wills.

I have suggested by my title that there are two identifiable cultures in dentistry. These have become increasingly apparent in the debate over health care reform and dentistry's participation in reform. I will designate them the culture of profession and the culture of the proprietary. While I acknowledge that such depictions are susceptible to the errors and fallacies of all generalizations, culture itself is a generic construct. The characterizations I will make can be instructive in understanding the current tension. I want to examine these two cultures using the definition and understanding of culture I have advanced. What are the norms, values, assumptions, beliefs, standards, and attitudes of these two cultures?

\section{The Culture of Profession}

Abraham Flexner helped establish our contemporary criteria for what constitutes a profession by identifying six cardinal characteristics of a profession. I will mention only one. He said, "professtons ... are organs contrived for the achievement of social ends rather than as bodies formed to stand together for the assertion of rights or for the protection of interests and privileges of their members." 5 Talcott Parsons, the dean of modern American sociology, states that "the core criterion of a full-fledged profession is that it must have means of ensuring that its competencies are put to socially responsible uses." He goes on to say "professionals are not capitalists ... and they certainly are not independent proprietors or members of proprietary groups. ${ }^{6}$ The designation "profession" is not self-appropriated, but is a sociological notion, an approbation of society; earned as a result of achieving specific criteria. Professions and professionals are professions and professionals because they pursue the good of humanity, not primarily or necessarily their individual personal good. Professions and professionals are professions and professionals because they organize, not to protect their own interests, as do labor unions and trade associations, but rather to promote the public good. Professions and professionals are professions and professionals because they are committed to respecting the inherent worth, value, and good of each person as an end, and not simply as a means. Professions and professionals serve the "end" of human good. Professions and professionals do not make other humans only or simply a "means" to their good. Professions and professionals have professed a life-their profession becomes the commitment of that life. And, while professions and professionals derive financial gain from their life's passion, it is truly derivative; a by-product of pursuing their passion and fulfilling the promise they made in becoming a professional Profession is a vocation, a way of life, not only or simply a way of earning a living.

While I am speculating, it is certainly conceivable that the status of profession, which dentistry has enjoyed up until this time, is the legacy of previous generations of practitioners who, in advocating for fluoridation and prevention, were understood by the society as truly placing the public good above personal monetary gain.

Why this seeming extraordinary demand for professions to look initially and primarily to the good of others, rather than reflexively to their individual private good? I suspect it has to do with the power over people that comes from knowledge. Core to the concept of profession is higher education, a sophisticated knowledge base. The traditional professions are referenced as the learned' professions. Knowledge is power, and the historically acknowledged professions of law, medicine (including dentistry as a specialty of medicine), and the clergy, are groups that hold power over others, and their basic human needs; power based in knowledge. The legal profession has power over property, the health profession, power over person; and the clergy, power over providence. Such power requires the possession of considerable moral virtue, as such power is easily abused.

In the culture of profession the guiding rule or principle, the norm, is that oral health is a primary good; an end in itself. Means become subservient to ends in such a culture. Helping society and individuals gain the benefits of oral health makes methods, including delivery systems, subsidiary. This reflects a professional value in this debate, care and concern for people and their wellbeing. Large numbers of American people are disadvantaged; they do not have oral health. Over 100 million Americans people lack access to basic oral health services. In my native Kentucky, a recent survey of oral health status resulted in the following characterization of the region of the state in which I was reared: "the oral health of the Appalachian Counties of Kentucky is comparable to that of a Third World Country." The professional culture is a culture concerned with gaining the good of oral health for all Americans, however it can be gained. 
The assumption underlying this valuing is societal good. It is an assumption of openness, flexibility, and change regarding how to achieve this good. This culture places its trust and confidence in partnering with society. It believes that a relationship of cooperation, of reciprocity and mutuality, with society can help to bring about the good of oral health for all. Reallocating and realigning resources, both financial and human, can result in all Americans gaining oral health. The touchstone, or standard of reference, for the professional culture is social justice, fairness in the social contract; the attitude, egalitarianism. If oral health is a basic human need, and it is; then it is a basic human good. Therefore, all members of our citizenry should have the benefit of this basic good, regardless of their individual economic or societal circumstance.

I believe that to the extent the American Association of Dental Schools' published position on health care reform reflects the culture of the dental education community, to that extent, the culture of academe is a culture of profession.

\section{The Proprietary Culture}

In a recent presentation, I heard a Trustee of the American Dental Association say the future of our profession is on the line in health care reform; that the reform movement has the real potential to affect our rights and professional freedoms, and change our system of "private practice, freedomof-choice, fee-for-service dentistry which has served the public so well." He went on to say that we must "do whatever we can to protect the control we have of the profession, "indicating that his own component and constituent societies had already begun advocating for "thetr best interests." 8

Our colleague's comments reflect the proprietary culture in dentistry in America today. In that culture, the individual and the individual rights are paramount. The dentist is one who, through personal initiative and discipline, has earned the right to offer dental services. Similarly, patients have a right to seek from whomever, whatever care they want and can afford. The preservation of the traditional prerogatives of autonomy and control by the dentist is a principle not to be violated by society's priorities for distribution of health care resources. The domain of the dentist is a private domain, inaccessible to public scrutiny, public accountability, or public influence. The proprietary culture is transforming dentistry through the commercialization of dental care. Dentistry is becoming a commodity produced and sold in the marketplace for a profit. The marketplace is free enterprise. In such a free enterprise system, the business model of selling "cures" undermines the professional model - a model rooted in a tradition of "caring."

That which is the norm for the proprietary culture is to view oral health as a means. While there is not a strict dichotomization of ends and means, the thetoric suggests the relative significance of ends and means. Helping society gain the benefits of oral health is secondary to that which is a more foundational value. The primary value, or end, for the proprietary culture is entrepreneurial, building a business, a successful enterprise, with a focus on gross services provided and profit margin created. The culture values selling therapies. The assumption in this culture is the private, individual good; maximizing the personal benefit that comes from being a provider of dental therapies and services. The belief system of the culture of practice, that in which the practice culture places its trust and confidence, is free enterprise; selling dentistry as a fee-for-service commodity. The marketplace determines profit and thus becomes the standard for the culture of practice; the bottom line is the culture's uniform referent. Individuals who can afford to purchase services should be able to do so from the provider of their choice, at a fee designated for the service. Those who cannot - cannot. This characterization thus allows us to identify the attitude or emotional intentionality of the proprietary culture. It is a type of social Darwinism. The fittest, that is, the economically-able, can gain the good of oral health through purchasing it. If unfit economically, then oral health succumbs to the laws of nature. It is an attitude that is intensively libertarian. Even Adam Smith, ${ }^{9}$ the quintessential advocate of the free market, acknowledged that for a laissez-faire economy to function there must be a basic infrastructure, such as education, protection, and health, open to all. He indicated that the market functions beyond the infrastructure of these social goods, which should not necessarily be marketdriven or determined.

The culture of the proprietary does acknowledge the need to somehow manage the indigent, as long as they are managed in a separate system, like the Medicaid system we have today. However, such a two-tiered system of care allows practitioners to opt out of caring for the economically disadvantaged, as so many do today. Currently only 20 percent of our Medicaid-eligible children actually receive oral health services. Many fall prey to a delivery system that says, "Oh, I don't treat Medicaid patients." While such a position could possibly be defended in states where reimbursement rates are such that significant economic losses would be sustained by the dentist, many dentists in states where reasonable rates of reimbursement exist also adopt such a stance; effectively discriminating against this socio-economic-cultural group with the greatest prevalence of oral disease. As one colleague recently expressed it, a "system for the poor is a poor system."

I believe that to the extent the American Dental Association's published position on health care reform (1992) ref lects the culture of the prac- 
tice community, to that extent, the culture of practice today is a proprietary culture.

\section{CONTRASTS, CAVEATS, AND} CONCERNS

I have defined culture and analyzed the two cultures in dentistry which I believe are in tension in the current debate on health care reform. Let me summarize the contrasts. The norm of the culture of the proprietary is oral health as a means; for the culture of profession, oral health is an end. The value for the proprietary is profit from curing; for profession, caring. The assumption for the proprietary, the individual good; for profession, social good. The belief system of the proprietary is private market, free enterprise; for profession, societal partnerships in achieving oral health. The standard for the proprietary is the marketplace; for profession, social justice. The attitude of the proprietary culture is one of social Darwinism; for the professional culture, egalitarianism.

In drawing the contrasts I have it is easy to be misunderstood and for the conclusion to be reached that I am castigating the character of those in dentistry enmeshed in the proprietary culture. Such is not the case. I am not necessarily making moral judgments, rather drawing distinctions between the qualities and characteristics I see in the two cultures. There is nothing inherently or intrinsically immoral about any of the norms, values, assumptions, beliefs, standards, or attitudes I have attributed to the proprietary culture. To describe the differences between cultures, such as those between Arabs and Jews, between Kentuckians and Californians, between African-Americans and Euro-A mericans, or between the business community and the professional community, is not necessarily a rendering of moral judgement. In fact, the distinction I am drawing reflects the differences between the domains of business ethics and professional ethics. What I am saying is the proprietary is a culture that understands dentistry as like I.B.M., Delta Airlines, and Hyatt Hotels; and individual dentists as not dissimilar to local automobile dealers, grocery merchants, or haberdashers; that is, dentistry as a business. This contrasts with the principles and precepts historically and traditionally associated with being a profession.

To the extent we allow dentistry to succumb to the proprietary culture, a market culture, we allow dentistry to lose its status as a profession and become only a business; just another way of making money. Dental care becomes a commodity that dentists sell and patients buy. The dentist is a producer, the patient is a consumer, and the interaction between dentist and patient is only one of many transactions in the commercial marketplace. As Rashi Fein, health economist at Harvard, and mem- ber of the Institute of Medicine's panel studying the future of dentistry has said, "A new language has infected the culture of American health care. It is the language of the marketplace, of the tradesmen, and of the cost accountant. It is a language that depersonalizes both patients and health professionals and treats health care as fust another commodity. It is a language that is dangerous."10 Use of the word "infected" is an apt usage. For the proprietary culture has led, and continues to lead, to illness in our health care delivery system-an illness reflected in the poor oral health of many who need and deserve oral health, but because of their positioning in the marketplace are unable to purchase it. Dentists and patients being free in the private market rings as hollow justification for the existence of the poor oral health of many in our society. The "private practice, freedom-of-choice, fee-for-service" chorus rings with dissonance in the ears of poor children who suffer from pain and infection because their parents cannot purchase care from the local proprietor of such care; and rests uncomfortably in the face of our disadvantaged adults, including many of our elderly, who have been effectively priced out of the marketplace. What price do we really pay as a society for worshiping at the feet of this idol of individualism and practitioner autonomy? A society that does not care for its sick is not a moral community. In fact, the moral fabric of a society is best judged by how it treats it least advantaged citizens. The index of a nation's character is how it treats its under-classes. Neither the public good, nor the good of the profession is well-served by a proprietary culture.

\section{CONTEMPORARY ENLIGHTENMENT}

I am not sanguine regarding our ability to ease the tensions between the two cultures I see existent in dentistry today. Culture develops gradually and over an extended period of time; and cultural change occurs slowly. Adherence to the precepts of one's culture is strong. Paul Tillich, the distinguished 20th Century German-A merican theologian, has said "religion is the substance of culture, and culture the form of religion" 11 While there are vast implications to his thesis, one relevant to our current discussion is that cultural values are held religiously, that is, with a passionate concern, frequently approaching ultimacy. The two cultures in dentistry bring to our discussion of health care reform a type of religious faith. Unfortunately, such fervency does not lead to productive and thoughtful dialogue, nor to resolution or creative progress.

If there is any hope, it must come in the form that arrived in our world with the 18th Century Enlightenment. It is the hope that learning leads to understanding, and understanding leads to enlightenment, and enlightenment leads to change. The tension we have characterized is a tension between 
the public good and the private good. The Enlightenment of the 18th Century brought new social and political understandings. Among them was a keen appreciation and valuing of self-interest. But, there was the realization that our private good, our selfinterest, is ultimately grounded in the common good or the good of others, "enlightened self-interest." This Enlightenment idea proved to be foundational to the "republican"tradition upon which our Country was founded. Republican with a lowercase " $r$ " is, in its etymological roots, commonweal or the common good. It stresses that, while we are all self-interested, our self-interest is ultimately best served when we reflectively rise above it and focus on the common good of society. ${ }^{12}$

We must draw on this republican tradition to offer a corrective to an individualistic and proprietary culture. A call to pursue the common good is a call to pursue the good-a life of health, including oral health, and a life of well-being-in common! It is a formal acknowledgment that unless we are all stakeholders in the good society and the good life, ultimately none of us will be. ${ }^{13}$ It is an understanding that our personal best interest is served when we, in a burst of enlightenment, affirm that the other person's interests must be served as well. It is an acknowledgment of the essential qualities of cooperation, of reciprocity, of mutuality, in a civil society. It is intellectual enlightenment that is fundamental to the concept of being a profession.

While the notion of being a profession, and a professional, may sound and seem like an ethereal ideal, given our economic reality, it is, in fact, not. In this regard I quote a noted entrepreneur of the marketplace, the chief executive officer of General Motors at the apogee of its success, Charles E. Wilson, who in 1953, while appearing before a congressional committee, made a comment that is often misquoted. He is misquoted as saying what many would have expected him to say, given his business focus and leadership of America's largest corporation: "what is good for General Motors is good for the country!" In fact, that is not what he said, and he spent his entire life correcting people who misquoted him. What he said was "what is good for the country is good for General Motors! ${ }^{14}$ What is good for the oral health of all of our Nation's citizens is good for dentistry. However, we must be vigilant to ensure that we neither believe nor promulgate the reverse, that what is good for dentistry is good for the nation's oral health. We all acknowledge that such does not necessarily follow. In fact, this is the major error of the proprietary and will ultimately prove to be its Achilles heel. Even American business is re-awakening to the reality that putting customers (others) first, providing them with a quality product and service, addressing their interests as primary; is ultimately in the best interest of American business. Putting the oral health of our profession's patients first, and by our patients I include all of the people of America, is ultimately in the best interest of American dentistry.

\section{CONCLUSION}

As I argue for dentistry to be actively engaged in the current health care reform efforts, I am not necessarily advocating a dissolution of our current delivery system. It has much to commend it. I am not arguing for any specific delivery system; only a system that ensures high quality care accessible to all Americans, without economic, social, or cul tural barriers; a system that, based on its outcomes, enables us to say the American people have the benefit of oral health. I am advancing the position that we must eagerly debate how we can best bring over 100 million American citizens effectively into our oral health care delivery system. I do not know how. I do not know if anyone does. But, if our goal is the oral health of the American people, we must be open and flexible in investigating and evaluating all strategies available to achieve this good. To say that this is our goal, but to immediately follow (or precede) that vision with a declaration that there is only one way to accomplish it, the way we do it now, is antithetical to the attitude of science, and the scientist; which dentistry and dentists are or should be.

Even in a proprietary culture, it seems astounding that an enterprise would not eagerly seek to add over 100 million people to its customer base. Based on the current gross national expenditures for dentistry of approximately $\$ 40$ billion, such expansion could hypothetically increase the gross product in dentistry by 70 percent, or to $\$ 68$ billion. The argument frequently advanced is "as $a$ nation we can't afford it." In our current system of health care we seem to be able to afford everything else. Why should our profession not advocate for a reallocation of the costs of unnecessary, ineffective, and expensive tertiary medical procedures provided by physicians, many in the first or last few months or weeks of life, to a basic program of cost effective, high quality, primary oral health care, provided by dentists. The debate is currently underway and we must be participants. There is no doubt that society cannot afford to pay for all the health care the American people want. The current issue is really an issue of rationing health care. Rationing is deliberating on cost-benefit relationships; thinking rationally about ratios. Dentistry must be forceful in making the rational argument that basic, primary oral health care yields results that should give it significant priority in the health care budget of America.

I want to be a member of a professional culture, and a unified profession. I want to be a part of a profession of dentistry committed to health care reform; a profession committed to universal access, access no matter what one's social, eco- 
nomic, or cultural circumstance; access to what is being called "a decent basic minimum" of oral health. Universal access has been described as the "moral heart" of our national health care reform initiative. ${ }^{15}$ I want to be a member of a profession that acknowledges that the good of the profession is best achieved by vigorously pursuing the good of the public. I want to be a member of a profession that is characterized by society as a profession of practitioners caring, compassionately caring, for the oral health of America and all Americans. I want to be a member of a profession. I do not want to be a proprietor. America needs oral health care professionals, not proprietors of dental remedies.

My appeal is for these tuo cultures I have suggested exist in American dentistry to come together in meaningful dialogue; to establish points of common understanding and agreement; to attempt to harmonize, to whatever extent possible, the differences that exist; and to advocate with unity for the oral health of America. My appeal is for all of us in dentistry to work together with society to pursue the common good in oral health; which is the pursuit of the good of oral health ... in common!

\section{References}

1. Snow CP. Two cultures and the scientific revolution. New York: Cambridge University Press, 1959.
2. Kuh GD, Whitt $E$. The invisible tapestry, culture in American colkges and universities.

Washington:ERIC,ASHE, 1988.

3. Sergiovanni TJ, Corbally JE. Leadership and organizational culture. Urbana and Chicago: Untversity of Illinots Press, 1986.

4. Gibson J, Ivancevich J, Donnelly J. Organizations: structure, behavior, processes. Plano, Texas: Business Publications, 1988.

5. Flexner $A$. Is soctal work a profession? School and Society 1915;1:26, 901-11.

6. Parsons T. Professions. International Encyclopedia of Soctal Sciences, Volume 12. New York: Macminlian Company and Free Press, 1968.

7. Lewis G. personal communication.

8. Kentucky Dental Assoclation. House of Delegates Fall Session. Lexington, Kentucky, September 26, 1993.

9. Smith $A$. An inquiry into the nature and causes of the wealth of nations, (1776). Indianapols: Liberty Classics, 1981.

10. Fein $R$. What is wrong with the language of medicine? New Engl J Med 1982;306(14):863-4.

11. Tillich P. Theology of culture. New York: Oxford University Press, 1964.

12. Nash D. Values and health care reform. J Pub Health Dent 1993;53(2):67-9.

13. Bellah RN, Medsen R, Sullivan WM, Swidler A, Tipton SM. The good soclety. New York: Alfred A. Knopf, 1991.

14. Drucker $P$. The new soclety of organtzations. Harvard Business Review. September-October, 1992.

15. Gostin L. AMA News, September 27, 1993. Chicago: American Medical Association. 